\title{
Александр Голиков
}

Доктор социологических наук, доцент кафедры социологии и кафедры политической социологии социологического факультета Харьковского национального университета имени В.Н. Каразина

(iD) https://orcid.org/0000-0002-6786-0393

golikov@karazin.ua

\section{ПАНДЕМИЯ КАК ФАКТОР ТРАНСФОРМАЦИЙ ПРАКТИК НА УКРАИНСКОМ РЫНКЕ ТРУДА (НА ПРИМЕРЕ МОЛОДЕЖИ Г. ХАРЬКОВА)}

\author{
PANDEMIC AS A FACTOR OF TRANSFORMATIONS \\ OF PRACTICES ON THE UKRAINIAN LABOR MARKET \\ (ON THE EXAMPLE OF KHARKIV'S YOUTH)
}

D0I: 10.24917/ycee.2020.11.30-44

Аннотация: $\quad$ В с псатье иследуется проблематика влияния пандемии на процессы трансформации практик на украинском рынке труда. Для этого в качестве эмпирического кейса была выбрана молодежь одного из крупнейших мегаполисов Украины. Автор предлагает анализ результатов пилотного количественного исследования методом онлайн-опроса. В этом исследовании проводится анализ феноменальности и процессуальности трудовых практик молодежи города Харькова в условиях пандемической ситуации. Изменения в трудовых статусах, возникшие в результате пандемической ситуации, восприятие процессов изменений на рынке труда находятся в центре внимания автора статьи. В частности, в результате использования каскада методов анализа (факторный и кластерный) выделяются три группы респондентов (идеалисты, прагматики, профессионалы-материалисты), подробно исследуются их характеристики. Предлагаются выводы о структурах и потенциальных тенденциях изменений, о специфике трансформации практик на рынке труда украинских мегаполисов (на примере Харькова), а также о потенциальных группах риска с точки зрения возможных миграционных настроений и ориентаций.

Ключевые слова: пандемия, трудовые практики, онлайн-опросы, молодежь, Харьков, восприятие.

Abstract: $\quad$ The article examines the impact of pandemic on transformation processes of practices in the Ukrainian labor market. For this purpose, the youth of one of the largest Ukrainian cities was chosen as an empirical case. The author offers an analysis of the results of a pilot quantitative study using an online survey. This study analyzes the phenomenal and procedural aspects of young people's labor practices in Kharkiv in a pandemic situation. Changes in labor status, problems arising from the pandemic situation, perception of the processes of change in the labor market are in the center of attention of the author of the paper. In particular, as a result of the use of a cascade of methods of analysis (factorial and cluster), three groups of respondents (idealists, pragmatists, materialist-professionals) are distinguished, which are studied in detail in terms of their characteristics. Conclusions are offered on the structures and potential 
trends of change, on the specifics of the transformation of practices in the labor market of Ukrainian cities (on the example of Kharkiv), as well as on potential risk groups in terms of possible migratory attitudes and orientations.

Keywords: $\quad$ pandemic, labor practices, online polls, youth, Kharkiv, perception.

\section{Введение}

андемия коронавируса и ее импмикации, к которым, прежде всего, следует отнести карантинные мероприятия и изменения в социальных пространствах труда, образования, маркетинга, потребления, помитики, стаци в 2020 ГодУ ОАним из самыХ неожиданных, но вполне прогнозируемых явлений. С одной стороны, мы имеем дело с типичным «черным мебедем $\gg$, с Аругой - с давно прогнозируемой проблемой, с которой давно уже Аолжна бы а столкнуться современная глобамьная цивимизация и культура, в частности - с учетом ее интенсивной пространственной мобимьности, политической открытости ее подсистем с точки зрения перемещений и (пере)отнесения (в том числе и [ре]идентификации) мюдей к размичным сообществам, степени экономической взаимозависимости разцичных глобацьных кцастеров, стран, сообществ и регионов.

С этой точки зрения неудивитемьно, что пандемические события и их послеАствия упами на «унавоженную почву», выражением чего явАяется активная, интенсивная и экстенсивная реакция «общественного бессознательного», как бы это обозначим П. Бурдье (Burd'e, I993). Показатемьный срез этого нам

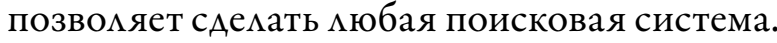
Например, поисковая система «Гуг » в 2020 г. предлагает нам следующие списки самых востребованных и активно используемых запросов (см. Табцицу г).

Мы видим, что более 6о\% всех запросов (в том числе и абсомютный «топ-го») перенасыщены запросами, напрямую (30-35\%) ими косвенно (30-35\%) касающимися коронавируса, его социамьных, экономических, медицинских, повсеАневностных, политических, образовательных измерений и последствий. Уже сам этот факт свидетемьствует о том, насколько актуацьна данная проблематика. Впрочем, знаниевый («что такое?»), практический («как?») и институционацьноэкономический (покупки) аспекты тоже не отстают, Аемонстрируя глубину проникновения в повсеАневность граждан Украины проблематики пандемии.

Таблица 1

Ton-10 запросов украинцев в поисковой системе Google в 2020 г. по разным категориям

\begin{tabular}{|c|c|c|c|}
\hline Toп-10 & Топ-10 покупок & Топ-10 «Что такое?» & Топ-10 «Как?» \\
\hline - коронавирус & - Маска медицинская & ... Пандемия & - как сшить маску \\
\hline - коронавирус рекомендации & - Пульсоксиметр & ... коронавирус & - как сделать антисептик для рук \\
\hline - Выборы в США & - Респиратор & ... локдаун & - как лечить коронавирус \\
\hline - Google Classroom & - iPhone 12 & ... дефолт & - как передается коронавирус \\
\hline - Симптомы коронавируса & - Антисептик & ... ау $\phi$ & - как правильно носить маску \\
\hline - На урок & - Глицерин & ... СНЮС & - как умерла Свинка Пеппа \\
\hline - Холостячка & - Парацетамол & ... краш & - как выйти замуж \\
\hline - Праздники 2020 & - Картина по номерам & ... кринж & - как вернуть обоняние \\
\hline - Карантин в Украине & - Кварцевая лампа & ... карантин выходного дня & - как сделать всё хорошо \\
\hline - Zoom & - Кислородный концентратор & ... чрезвычайное положение & - как удалить аккаунт в инстаграм \\
\hline
\end{tabular}


ОАнако в данной работе мы выбираем ее конкретный разрез. ГАобальность, системность, универсальность этого вызова переА обществом, политикой, экономикой, культурой, медиа, управлением такова, что ни одно партикулярное исследование не может отразить их даже схематически. Ааже если исследовать эту проблему по отношению к конкретной социальной группе (молодежь) или даже если сконцентрировать взгляА на конкретной подгруппе (молодежь Украины или молодежь Харькова), все же многомерность, во многом неопределенность, неразведанность и аморфность объекта исследования не позволяют описать его удовлетворительно.

В проявлениях и последствиях этой проблематики Аля харьковской молодежи мы специально обращаемся к экономическим, трудовым и профессиональным измерениям, которые полагаем особенно важными. Ведь именно проблема экономической и трудовой адаптации стала одной из самых острых в пандемические времена, о чем свидетельствуют даже уже проводившиеся исследования (Zizek, 2020; Klâjn, 2020). При этом молодежь, с одной стороны, предполагается и ожидается как наиболее гибкая и мабильная группа с высокоадаптивными тактиками и стратегиями (Martirosân, 2020), a с Аругой - гипотезируется и часто исследуется как одна из наиболее уязвимых к таким ситуациям групп (OECD, 2020; Novaâ molodežnaâ povestka, 202O; Turkulec, Turkulec, Listopadova, Sokol'skaâ, 2020) по разным причинам: то изза отсутствия стажа, то из-за недостаточной вкАюченности в социальные отношения, группы и институты, то оттого, что она находится на стартовых этапах своей профессионацьной траектории, то оттого, что она обладает совсем другими по сравнению с преАЫАущими поколениями ценностями труда. Этот комплекс противоречий и стац предметом нашего исследования, а его це-

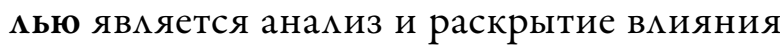

пандемической ситуации и ее последствий (карантина, экономических проблем, трудовых трансформаций) на рынок труда момодежи украинского мегаполиса на примере Харькова.

\section{Теоретические и эмпирические основы исследования}

Теоретические наработки по Аанной тематике содержатся в:

- исследованиях экономической активности молодежи (Zaharkina, Alëhina, Mosina, 2020; Martirosân, 2020);

- эскизном и иногда наивном, но все же профессионацьном анализе социологами, философами, экономистами, политологами, культурологами феноменацьности и процессуацьности проживания обще-

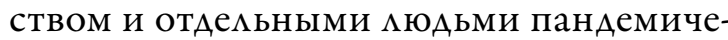
ской ситуации, карантинных мероприятий и связанных с ними экономических, политических, организационных, административных последствий (Mironova, 2020; Volkov, Kurbatov, 2020; Hasuev, 202O; Agamben, 2020; Fukuyama, 2020);

- исследованиях ценностей молодежи, где отде нас разработки (Sokurânskaâ, 2006). Исскедование ценностей молодежи позволяют выходить на матентные переменные, которые детерминируют ценностные комплексы и порожАают цемые группы, выделенные именно по ценностным признакам (Sokurânskaâ, Kislova, 2003);

- Аискурсе практик (Volkov, Harhordin, 2008), из которого мы берем прежде всего понимание практик как устойчивых, воспроизводимых, структурно определенных, синтетически существующих (то есть на микро- и на макроуровне) систем действия, воспроизводящихся прежде всего 
как неосознаваемые (а не рефлексивные) «автоматически» и связанные с ценностями, схемами восприятия / оценивания, «доксичными» (Burd'e, 1996) структурами и т.п. Именно такой взгляА позволяет

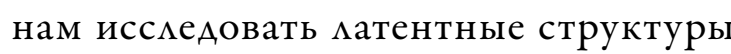
Аетерминации, причем такое исследование оказывается более свободным от строгих требований к репрезентативности (об этом см. ниже), чем исследования проявлений, тенденций и измерений, где действительно важна репрезентативность исследования.

Эмпирической основой исследования стац онцайн-опрос в технике индивидуацьного формализованного анкетирования, полевой этап которого бым проведен I- 5 декабря 2020 г. ${ }^{1}$ Выборка составила II9 респондентов преимущественно молодежных социальных групп (где преАставители старших социальных групп были рекрутированы прежде всего А я создания возможности сравните ьного анализа), техника рекрутинга - заочная, «снежный ком». Инструмент проведения - Google-формы дмя опроса. Аанные быми обработаны и проанализированы в IBM SPSS Statistics v.23. В силу специфики выборки и ее небольшого размера Аанные во всех таблицах мы предостав яем как в относительных (Аля возможности сравнения групп), так и в абсолютных (Аля учета специфики величины выборки) величинах.

Полевой этап исследования бым проведен прежде всего усилиями магистрантки социологического факультета ХНУ имени В.Н. Каразина $\Lambda$ ины Станиславовны Головешко, которой мы благодарны за сотрудничество и возможность приобщиться к такой интересной теме; программирование исследования и конструирование инструментария было осуществлено совместными усимиями автора статьи и $\Lambda . С$. Головешко. Обработка и анамиз результатов, представленные в статье - авторские.

\section{Карантин как фактор на рынке труда Харькова: общий эскиз}

Прежде всего, показательным явмяется общее состояние восприятия молодыми харьковчанами рынка труда и себя на его фоне. И здесь мы обнаруживаем достаточно оптимистичную картину: в частности, почти половина $(49,6 \%)$ заявими, что вообще работают в обычном режиме, еще треть (31,1\%) работают Аистанционно. Таким образом, только пятая часть респондентов так или иначе столкнуАась с существенными (Аистанцирование работы мы считаем важным, однако не влияющим на саму сущность труда) изменениями своего профессионацьного статуса: в частности, I2,6\% заявили, что находятся в поисках работы, а 5,9\% - что находятся в отпуске по желанию своему или работодателя. Увольнение же вообще оказывается реАким актом, как минимум Аля харьковской молодежи.

Коррелируются с этим и распределения возникновения проблем в связи с карантином. 65,5\% заявило, что они не столкнулись ни с какими проблемами, 24,3\% - что у них есть проблемы с заработной платой (9,2\% - что она уменьшена, I5,I\% - что ее задерживают), еще $5 \%$ получими предложение уйти в неоп ачиваемый отпуск, І,7\% - преАложение уволиться.

Неудивительно, что при измерении обобщенного ощущения наших респондентов относительно их трудоустройства мы обнаружими, что почти три четверти так ими иначе оценивают влияние карантинных мер на своем трудоустройстве как непроблематичное (4I,2\% не ощутили никаких проблем, I8,5\% заявици, что прекрасно справ яются с Аистанционной работой, І2,6\% уже вернулись к стандартному режиму работы посме выхода на дистанционную форму). Среди выявленных проблем важнейшими явцяются поиск работы (го, \%), наличие только временных вариантов заработка $(8,4 \%)$ и продолжительность поиска работы $(6,7 \%)$. 
На базе послеАнего признака мы вычменими Аве группы: тех, у кого возникли проблемы (последние три подгруппы), и тех, у кого не возникАо пробкем (первые три группы), - и проанализировали сущность возникших проблем в восприятии преАставитемей этих групп (см. Таблицу 2).

Как видим, среди тех, кто ищет работу, ІІ из I4 респондентов (то есть почти четыре пятых) ищут работу именно вследствие карантинных мероприятий, среди тех, кто работает стационарно, около го\% заявили, что у них возникли проблемы (то есть если ты продолжаешь работать стационарно, то у тебя 9 шансов из го чувствовать себя относительно комфортно на рынке труда), среди тех, кто работает удаленно - около 25\% (здесь шансы снижаются Ао 3 из 4). Итак, карантин несколько углубцяет уже имеющиеся проблемы, дематентизирует до сих пор матентизированное и обостряет заложенные в систему противоречия, а не порождает - по крайней мере, пока что и на Аанный момент - принципиально новые.

Интересные и парадоксальные уточнения мы получаем, когда исследуем, каковы именно последствия карантина Аля проблемных групп (см. Табцицу 3).

В частности, оказывается, что в абсолютных показателях с задержками зарплаты столкнуАись сопоставимые подгруппы респондентов как среди тех, у кого, по самооценке, не возникмо проблем, так и среАи тех, у кого они возникли, а с уменьшением зарплаты - и в абсолютных, и в относительных показателях в группе «непроблематичных» Ааже больше

Таблица 2

В чем именно заключаются проблемы для проблемных групп, в прочентах и абсолютных показателях

\begin{tabular}{|c|c|c|c|c|c|c|c|c|}
\hline Проблемь & & Ищут работу & Уволены & В отпуске & $\begin{array}{c}\text { В отпуске по } \\
\text { собственному } \\
\text { желанию }\end{array}$ & $\begin{array}{l}\text { Работают } \\
\text { удаленно }\end{array}$ & $\begin{array}{c}\text { Работают } \\
\text { стационарно }\end{array}$ & Bcero \\
\hline \multirow{2}{*}{ Возникли } & $\mathrm{N}$ & 11 & 1 & 2 & 1 & 9 & 6 & 30 \\
\hline & $\%$ & $36,7 \%$ & $3,3 \%$ & $6,7 \%$ & $3,3 \%$ & $30,0 \%$ & $20,0 \%$ & $100,0 \%$ \\
\hline \multirow{2}{*}{$\begin{array}{l}\text { Не } \\
\text { возникли }\end{array}$} & $\mathrm{N}$ & 3 & 0 & 1 & 3 & 28 & 50 & 86 \\
\hline & $\%$ & $3,5 \%$ & $0,0 \%$ & $1,2 \%$ & $3,5 \%$ & $32,6 \%$ & $58,1 \%$ & $100,0 \%$ \\
\hline \multirow{2}{*}{ Всего } & $\mathrm{N}$ & 15 & 1 & 3 & 4 & 37 & 56 & 119 \\
\hline & $\%$ & $12,6 \%$ & $0,8 \%$ & $2,5 \%$ & $3,4 \%$ & $31,1 \%$ & $47,1 \%$ & $100,0 \%$ \\
\hline
\end{tabular}

Таблица 3

Последствия карантина для проблемных групп харьковской молодежи, в процентах и абсолютных показателях

\begin{tabular}{lccccccc}
\hline & $\begin{array}{c}\text { Проблем не } \\
\text { возникло }\end{array}$ & $\begin{array}{c}\text { Задержки } \\
\text { зарплаты }\end{array}$ & $\begin{array}{c}\text { Предложили } \\
\text { уволиться }\end{array}$ & $\begin{array}{c}\text { Предложили } \\
\text { неоплачива- } \\
\text { емый отпуск }\end{array}$ & $\begin{array}{c}\text { Уменьшили } \\
\text { зарплату }\end{array}$ & Всего \\
\hline \multirow{2}{*}{ Возникли } & $\mathrm{N}$ & 10 & 10 & 2 & 5 & 2 & 30 \\
\hline & $\%$ & $33,3 \%$ & $33,3 \%$ & $6,7 \%$ & $16,7 \%$ & $6,7 \%$ & $100,0 \%$ \\
\hline \multirow{2}{*}{$\begin{array}{l}\text { Везникли } \\
\text { вози }\end{array}$} & $\mathrm{N}$ & 68 & 8 & 0 & 1 & 9 & 86 \\
\hline \multirow{2}{*}{ Всего } & $\mathrm{N}$ & $78,1 \%$ & $9,3 \%$ & $0,0 \%$ & $1,2 \%$ & $10,5 \%$ & $100,0 \%$ \\
\hline
\end{tabular}


(в абсолютных - вчетверо больше, в относительных - в полтора раза). Это уже свидетельствует о том, что карантинная ситуация рутинизировацась в общественном сознате ьном и бессознательном, и они такие проблемы, как задержки или уменьшение зарплаты, часто не воспринимают как проблемы, достойные упоминания. Это явАяется и тревожным знаком: ведь это позволяет усилить эксплуатацию (в виде дополнительных рабочих часов, уменьшения зарплаты, свертывания социальных программ и пакетов, изменений в графике и т.п.), воспринимаемую как «непременное змо» и «то, без чего никуда». Но во всем остальном мы имеем достаточно прогнозируемую ситуацию с точки зрения распределения проблем.

Установив это, мы должны обратиться к внутренним структурам этих групп. ПараАокса ьно Аһя господствующего в научном Аискурсе взгляда на гендерные неравенства на рынке труда оказалось, что среди женщин нескол ько больше тех, у кого проблем не возникмо. Если среАи числа последних 57,0\% женщин, то среди тех, у кого возникми проблемы, - 53,3\%. В этом смысле мы имеем несколько парадоксальную ситуацию невоспроизводства привычных и известных гендерных неравенств, Аифференциации и дискриминации. ОАнако окончательные выводы по этому поводу декать еще рано, этот вопрос требует более детального исследования.

В целом же мы обнаружими некоторое вАияние образовательного и возрастного факторов (см. Таблицу 4) и более слабое семейного фактора (см. Таблицу 5), причем еАинственной группой среАи возрастных групп, которая оказа ась «слишком» оптимистичной, явАяется группа между 20 и 23 годами, где существенно преобладают те, кто оценил свои проблемы как несущественные.

А вот фактор образования оказался очень сильным. В частности, наличие научной

Таблица 4

Образовательная и возрастная структура разнопроблемных групп в условиях карантина, в процентах и абсолютных показателях

\begin{tabular}{|c|c|c|c|c|c|c|c|c|}
\hline \multirow{2}{*}{\multicolumn{2}{|c|}{$\begin{array}{c}\text { Возрастные } \\
\text { группы }\end{array}$}} & \multicolumn{3}{|c|}{ Возникли проблемы } & \multirow{2}{*}{$\begin{array}{c}\text { Уровень } \\
\text { образования }\end{array}$} & \multicolumn{3}{|c|}{ Возникли проблемы } \\
\hline & & \multirow{2}{*}{ Да } & \multirow{2}{*}{$\begin{array}{c}\text { Нет } \\
7\end{array}$} & \multirow{2}{*}{$\begin{array}{c}\text { Всего } \\
13\end{array}$} & & \multirow{2}{*}{$\begin{array}{c}\text { Да } \\
0\end{array}$} & \multirow{2}{*}{$\begin{array}{c}\text { Нет } \\
9\end{array}$} & \multirow{2}{*}{$\begin{array}{c}\text { Bcero } \\
9\end{array}$} \\
\hline 10 & $\mathrm{~N}$ & & & & & & & \\
\hline HO & $\%$ & $13,3 \%$ & $8,1 \%$ & $10,9 \%$ & 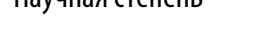 & $0,0 \%$ & $10,5 \%$ & $7,6 \%$ \\
\hline \multirow{2}{*}{$20-23$} & $\mathrm{~N}$ & 6 & 26 & 32 & \multirow{2}{*}{ Высшее } & 11 & 45 & 57 \\
\hline & $\%$ & $20,0 \%$ & $30,2 \%$ & $26,9 \%$ & & $36,7 \%$ & $52,3 \%$ & $47,9 \%$ \\
\hline \multirow{2}{*}{$24-29$} & $\mathrm{~N}$ & 9 & 23 & 32 & \multirow{2}{*}{ Неполное высшее } & 10 & 18 & 29 \\
\hline & $\%$ & $30,0 \%$ & $26,7 \%$ & $26,9 \%$ & & $33,3 \%$ & $20,9 \%$ & $24,4 \%$ \\
\hline \multirow{2}{*}{$30-35$} & $\mathrm{~N}$ & 6 & 14 & 20 & \multirow{2}{*}{ Среднее специальное } & 6 & 8 & 14 \\
\hline & $\%$ & $20,0 \%$ & $16,3 \%$ & $16,8 \%$ & & $20,0 \%$ & $9,3 \%$ & $11,8 \%$ \\
\hline \multirow{2}{*}{$36-50$} & $\mathrm{~N}$ & 5 & 14 & 19 & \multirow{2}{*}{ Среднее } & 2 & 4 & 7 \\
\hline & $\%$ & $16,7 \%$ & $16,3 \%$ & $16,0 \%$ & & $6,7 \%$ & $4,7 \%$ & $5,9 \%$ \\
\hline \multirow{2}{*}{ Более 51 лет } & $\mathrm{N}$ & 0 & 2 & 2 & \multirow{2}{*}{ Неполное среднее } & 1 & 2 & 3 \\
\hline & $\%$ & $0,0 \%$ & $2,3 \%$ & $1,7 \%$ & & $3,3 \%$ & $2,3 \%$ & $2,5 \%$ \\
\hline \multirow{2}{*}{ Всего } & $\mathrm{N}$ & 30 & 86 & 119 & \multirow{2}{*}{ - Всего } & 30 & 86 & 119 \\
\hline & $\%$ & $100,0 \%$ & $100,0 \%$ & $100,0 \%$ & & $100,0 \%$ & $100,0 \%$ & $100,0 \%$ \\
\hline
\end{tabular}


степени (почти директивно) и высшего образования (менее жестко) влияет на (само) идентификацию респондента как члена «непроблематичной» группы, а кмючевыми носителями проблем с трудоустройством и экономической самореализацией явмяются группы граждан с неполным высшим и среАним специацьным образованием.

Что же касается семейных статусов, то мы видим несколько большую (хотя и слабую) защищенность тех, кто находится в зарегистрированном браке, однако при этом заметно большую защищенность тех, у кого нет детей. Причем последнее - вне зависимости от того, планируют они заводить детей в ближайшее время или нет; и здесь мы можем предполагать, что решающим фактором является не столько ориентация на детей, сколько объективный факт их нацичия и, соответственно, отвлечения внимания, ресурсов и т.п. на воспитание ребенка. При этом наибомее рискованной группой оказываются те, у кого есть один ребенок (с одной стороны, это одна из самых значительных среди молодых групп украинцев (Ао 35 Ает, заметим), с Аругой - достаточно экономически активная).

Уже указанная нами вышеотвергнутая гипотеза ценностей показывает, что ценностной детерминацией молодежных шансов на рынке труда мы также интересовацись. И здесь естественным является обращение, прежде всего, к месту ценностей труда (см. Таблицу 6) в ценностной структуре молодежи. Мы обнаруживаем, что явственно более успешной явцяется группа тех, Аля кого работа занимает наиболее важное место, - в ней Аиспропорционацьно относительно выборочной совокупности преоб-

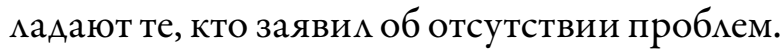

Заметим, что среАи тех, Аля кого проблемы все же возникми, несколько больше тех, кто относится к работе с меньшим энтузиазмом, хотя эта зависимость не является ярко выраженной (кроме, собственно, вышеуказанного «протуберанца» в распределении). При этом вопрос о ценности карьерного роста не дает даже такого показателя: оказывается, что среди тех, у кого возникми проблемы, несколько больше откровенных карьеристов (40,0\% против

Таблица 5

Семейные статусы и стратегии разнопроблемных групп в условиях карантина, в процентах и абсолютных показателях

\begin{tabular}{|c|c|c|c|c|c|c|c|c|}
\hline \multicolumn{6}{|c|}{ Возникли проблемы } & \multicolumn{3}{|c|}{ Возникли проблемы } \\
\hline \multicolumn{2}{|l|}{ Статус } & Да & Нет & Всего & Дети & Да & Нет & Всего \\
\hline \multirow{2}{*}{ Вне брака } & $\mathrm{N}$ & 16 & 43 & 59 & \multirow{2}{*}{$\begin{array}{l}\text { Нет и не } \\
\text { планируют }\end{array}$} & 13 & 43 & 58 \\
\hline & $\%$ & $53,3 \%$ & $50,0 \%$ & $49,6 \%$ & & $43,3 \%$ & $50,0 \%$ & $48,7 \%$ \\
\hline \multirow{2}{*}{$\begin{array}{l}\text { Зарегистрированный } \\
\text { брак }\end{array}$} & $\mathrm{N}$ & 8 & 27 & 35 & \multirow{2}{*}{$\begin{array}{l}\text { Нет, но } \\
\text { планируют }\end{array}$} & 4 & 17 & 22 \\
\hline & $\%$ & $26,7 \%$ & $31,4 \%$ & $29,4 \%$ & & $13,3 \%$ & $19,8 \%$ & $18,5 \%$ \\
\hline \multirow{2}{*}{ Гражданский брак } & $\mathrm{N}$ & 4 & 10 & 14 & \multirow{2}{*}{ Да, один } & 9 & 15 & 24 \\
\hline & $\%$ & $13,3 \%$ & $11,6 \%$ & $11,8 \%$ & & $30,0 \%$ & $17,4 \%$ & $20,2 \%$ \\
\hline \multirow{2}{*}{ Разведены } & $\mathrm{N}$ & 2 & 6 & 8 & \multirow{2}{*}{ Да, ДВое } & 3 & 10 & 13 \\
\hline & $\%$ & $6,7 \%$ & $7,0 \%$ & $6,7 \%$ & & $10,0 \%$ & $11,6 \%$ & $10,9 \%$ \\
\hline \multirow{4}{*}{ Всего } & $\mathrm{N}$ & 30 & 86 & 119 & \multirow{2}{*}{ Больше двух } & 1 & 1 & 2 \\
\hline & $\%$ & $100,0 \%$ & $100,0 \%$ & $100,0 \%$ & & $3,3 \%$ & $1,2 \%$ & $1,7 \%$ \\
\hline & & & & & \multirow{2}{*}{ Всего } & 30 & 86 & 119 \\
\hline & & & & & & $100,0 \%$ & $100,0 \%$ & $100,0 \%$ \\
\hline
\end{tabular}


Таблица 6

Место ценности труда для разнопроблемных групп, в процентах и абсолютных показателях

\begin{tabular}{|c|c|c|c|c|}
\hline \multirow{2}{*}{$\begin{array}{l}\text { «Укажите, пожалуйста, какое место } \\
\text { в Вашей жизни занимает работа?» }\end{array}$} & & \multicolumn{3}{|c|}{ Проблемы в работе от карантина } \\
\hline & & Возникли & Не возникли & Всего \\
\hline \multirow{2}{*}{ Наиболее значимое место, это основа моей жизни } & $\mathrm{N}$ & 2 & 11 & 13 \\
\hline & $\%$ & $6,7 \%$ & $12,8 \%$ & $10,9 \%$ \\
\hline \multirow{2}{*}{ Более значимое место, чем другие виды деятельности } & $\mathrm{N}$ & 8 & 20 & 28 \\
\hline & $\%$ & $26,7 \%$ & $23,3 \%$ & $23,5 \%$ \\
\hline \multirow{2}{*}{$\begin{array}{l}\text { Значима для меня в равной степени с личной жизнью, } \\
\text { досугом, хобби и т.д. }\end{array}$} & $\mathrm{N}$ & 13 & 36 & 51 \\
\hline & $\%$ & $43,3 \%$ & $41,9 \%$ & $42,9 \%$ \\
\hline \multirow{2}{*}{$\begin{array}{l}\text { Работа занимает менее значимое место, чем другие виды } \\
\text { деятельности }\end{array}$} & $\mathrm{N}$ & 4 & 9 & 14 \\
\hline & $\%$ & $13,3 \%$ & $10,5 \%$ & $11,8 \%$ \\
\hline \multirow{2}{*}{$\begin{array}{l}\text { Наименее значимое место: в жизни есть более интересные } \\
\text { вещи }\end{array}$} & $\mathrm{N}$ & 2 & 6 & 8 \\
\hline & $\%$ & $6,7 \%$ & $7,0 \%$ & $6,7 \%$ \\
\hline \multirow{2}{*}{ Затрудняюсь ответить } & $\mathrm{N}$ & 1 & 4 & 5 \\
\hline & $\%$ & $3,3 \%$ & $4,7 \%$ & $4,2 \%$ \\
\hline \multirow{2}{*}{ Всего } & $\mathrm{N}$ & 30 & 86 & 119 \\
\hline & $\%$ & $100,0 \%$ & $100,0 \%$ & $100,0 \%$ \\
\hline
\end{tabular}

30,2\% среди тех, у кого проблем не возникцо), однако это компенсируется тем, что респонАентов, ААя которых карьерный рост «скорее важен», среди тех, у кого проблемы не возникают, 5I,2\% (против 43,3\% в Аругой категории).

Иуж совсем парадоксальные распределения мы видим в такой связанной с экономическими и профессиональными практиками ценностной сфере, как восприятие трудовых мигрантов, которое мы измерили при помощи специаАьно модифицированной под данную задачу шкалы Богардуса, учитывая конструктивистскую и биографическую (а не примордиальную и историческую) сущность идентичности и статуса трудового мигранта (см. Таблицу 7).

С одной стороны, группа «непроблематичных» содержит несколько большее количество «абсолютно толерантных»; однако, с Аругой, при этом она же демонстрирует нацичие значительно преАстав енной (суммарно Іо, \%) группы респондентов, ксенофобски и Аистанцированно настроенных относительно трудовых мигрантов. В целом разницы не настолько глубоки и выражены, чтобы демать какие-то окончательные выводы, однако можно выдвинуть некоторые важные и интересные гипотезы.

Во-первых, мы видим среди тех, кто (еще?) сохраним свое рабочее место, распространение ксенофобской защитной реакции на карантинные и пандемические события.

Во-вторых, мы наблюдаем апроприацию «пострадавшими» чувств и аффектов трудовых мигрантов, и с этой точки зрения их реакция на потенциацьный контакт с таковыми смягчается.

B-третьих, мы можем заметить поляризацию группы тех, кто сохранил работу, на тех, кто сохраним ее в результате жесткой борьбы (в которой получим опыт профессионацьного и экономического противостояния Аругому), и на тех, кто сохранил этот статус бцагодаря своему высокому профессионаАизму и вовлеченности в глобальные процессы трудоустройства (что, как минимум 
Таблица 7

Восприятие трудовых мигрантов представителями разнопроблемных групп, в процентах и абсолютных показателях

\begin{tabular}{|c|c|c|c|c|}
\hline \multirow{2}{*}{\multicolumn{2}{|c|}{$\begin{array}{l}\text { Насколько близко Вы готовы иметь дело с трудовыми мигрантами, } \\
\text { сделать их частью своей жизни? }\end{array}$}} & \multicolumn{2}{|c|}{ Проблемы... } & \multirow[t]{2}{*}{ Bcero } \\
\hline & & Возникли & Не возникли & \\
\hline \multirow{2}{*}{ Затрудняюсь ответить } & $\mathrm{N}$ & 8 & 19 & 23 \\
\hline & $\%$ & $26,7 \%$ & $22,1 \%$ & $19,3 \%$ \\
\hline \multirow{2}{*}{$\begin{array}{l}\text { Готов, чтобы члены моей семьи становились трудовыми мигрантами - } \\
\text { или чтобы трудовой мигрант стал родственником. }\end{array}$} & $\mathrm{N}$ & 9 & 28 & 39 \\
\hline & $\%$ & $30,0 \%$ & $32,6 \%$ & $32,8 \%$ \\
\hline \multirow{2}{*}{$\begin{array}{l}\text { Готов, чтобы мои близкие друзья становились трудовыми мигрантами - } \\
\text { или чтобы трудовой мигрант стал другом }\end{array}$} & $\mathrm{N}$ & 6 & 16 & 22 \\
\hline & $\%$ & $20,0 \%$ & $18,6 \%$ & $18,5 \%$ \\
\hline \multirow{2}{*}{$\begin{array}{l}\text { Готов, что кто-то из моих соседей окажется трудовым мигрантом - или } \\
\text { чтобы таковой появился среди моих соседей }\end{array}$} & $\mathrm{N}$ & 3 & 5 & 8 \\
\hline & $\%$ & $10,0 \%$ & $5,8 \%$ & $6,7 \%$ \\
\hline \multirow{2}{*}{$\begin{array}{l}\text { Готов, чтобы кто-то из моих коллег стал трудовым мигрантом - или } \\
\text { чтобы таковой стал одним из моих коллег }\end{array}$} & $\mathrm{N}$ & 4 & 9 & 13 \\
\hline & $\%$ & $13,3 \%$ & $10,5 \%$ & $10,9 \%$ \\
\hline \multirow{2}{*}{ Готов принять их только как граждан своей страны, но не ближе } & $\mathrm{N}$ & 0 & 6 & 6 \\
\hline & $\%$ & $0,0 \%$ & $7,0 \%$ & $5,0 \%$ \\
\hline \multirow{2}{*}{$\begin{array}{l}\text { Готов воспринять их как неграждан, гостей моей страны; таких нужно } \\
\text { лишать гражданства }\end{array}$} & $\mathrm{N}$ & 0 & 3 & 3 \\
\hline & $\%$ & $0,0 \%$ & $3,5 \%$ & $2,5 \%$ \\
\hline \multirow{2}{*}{ Всего } & $\mathrm{N}$ & 30 & 86 & 119 \\
\hline & $\%$ & $100,0 \%$ & $100,0 \%$ & $100,0 \%$ \\
\hline
\end{tabular}

на декцаративном уровне, работает на толерантность и ее манифестации).

Какая из этих гипотез явмяется релевантной, могут показать только дацьнейшие исследования, к тому же проведенные на более широких и более строго сконструированных выборках. Но некоторые аспекты этих гипо-

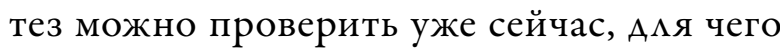
мы и обращаемся к более глубоким методам анализа данных (см. далее).

\section{Три фактора, три кластера, три ценностные группы}

Именно с этой целью мы обращаемся к анаАизу ценностной среды наших респондентов и, в частности, их факторной детерминации (см. Таблицу 8). Мы покучими факторный анализ с не очень высоким, однако приеммемым показателем суммарной дисперсии $(57,3 \%)$.

Таблица 8

Три выделенных фактора и объясненная ими совокупная дисперсия

\begin{tabular}{lcccccc}
\hline & \multicolumn{2}{c}{ Начальные собственные значения } & \multicolumn{2}{c}{ Ротация суммы квадратов нагрузок } \\
\cline { 2 - 7 } Компонент & Всего & $\begin{array}{c}\text { Процент } \\
\text { дисперсии }\end{array}$ & $\begin{array}{c}\text { Суммарный } \\
\text { процент }\end{array}$ & Всего & $\begin{array}{c}\text { Процент } \\
\text { дисперсии }\end{array}$ & $\begin{array}{c}\text { Суммарный } \\
\text { процент }\end{array}$ \\
\hline 1 & 3,909 & 35,539 & 35,539 & 2,313 & 21,029 & 21,029 \\
\hline 2 & 1,220 & 11,095 & 46,634 & 2,187 & 19,884 & 40,913 \\
\hline 3 & 1,176 & 10,693 & 57,327 & 1,805 & 16,413 & 57,327 \\
\hline
\end{tabular}


В ротированном виде эти факторы преАставлены в Таблице 9, где мы видим, что признаки распределяются между этими факторами достаточно однозначно (разве что «престижность работы» имеет несколько маргинацьный / пограничный статус). Соответственно, содержательная интерпретация этих факторов хотя и вызвала некоторые проблемы, но все же тоже явцяется однозначной.

Таким образом, мы имеем дело с тремя факторами:

- профессионализм - самый большой по Аисперсии и влиятельный фактор, который коррелирует с уровнем оплаты труда, отношениями с руковоАством, условиями труда и комлективом.

- комфорт - второй по влиятельности фактор, который коррелирует с соответствием должности уровню образования и специальности, удобством расположения рабочего места, социальными мьготами и престижностью работы.

- постматериализм - наиболее слабый (что, учитывая украинскую экономическую ситуацию, и неудивительно) из факторов, вкцючающий такие ценности труда, как возможности профессионацьного развития, карьерного роста и возможность приносить пользу окружающим.

Уже сами по себе эти факторы явцяются показательными. Оказывается, мы действительно имеем отдельный фактор профессионализма, который сам по себе, вне зависимости от отношения к конкретному Аругому или вообще к Аругому как к чемовеку, влияет

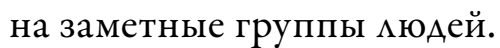

ОАнако Аля того, чтобы исследовать природу этих факторов на конкретных социацьных группах, мы осуществили кмастеризацию нашей выборки на базе этого факторного анализа (см. Табцицу го).

3Аесь у нас выстроилось три группы, которые, учитывая их связь с тем или иным фактором, были нами обозначены как: I) «прагматики» (учитывая их относительно индифферентную позицию в отношении постматериализма (но все же с мегкой противонаправленностью), комфорта (все же с мегкой

Таблица 9

Содержательные аспекты выделенных факторов и их интерпретация

\begin{tabular}{|c|c|c|c|}
\hline \multirow{2}{*}{$\begin{array}{c}\text { Метод выделения факторов: метод главных } \\
\text { компонент; метод вращения: Варимакс } \\
\text { с нормализацией Кайзера; вращение сошлось за } 7 \\
\text { итераций }\end{array}$} & \multicolumn{3}{|c|}{ Компонент } \\
\hline & $\begin{array}{l}1 \text { - профес- } \\
\text { сионализм }\end{array}$ & 2 - комфорт & $\begin{array}{c}3 \text { - постмате- } \\
\text { риализм }\end{array}$ \\
\hline Уровень оплаты труда & 0,795 & 0,034 & $-0,002$ \\
\hline Отношения с руководством & 0,645 & 0,255 & 0,172 \\
\hline Условия труда & 0,587 & 0,331 & 0,188 \\
\hline Коллектив & 0,519 & 0,189 & 0,276 \\
\hline Соответствие должности уровню образования и специальности & $-0,034$ & 0,821 & 0,240 \\
\hline Удобство расположения рабочего места & 0,310 & 0,728 & 0,008 \\
\hline Возможность получения социальных льгот & 0,274 & 0,624 & 0,136 \\
\hline Престижность работы & 0,432 & 0,497 & 0,039 \\
\hline Возможность профессионального развития, самореализации & 0,267 & 0,002 & 0,766 \\
\hline Возможность приносить пользу окружающим & $-0,0142$ & 0,359 & 0,754 \\
\hline Возможности для карьерного роста & 0,449 & 0,082 & 0,657 \\
\hline
\end{tabular}


Конечные чентры кластеров, построенных по результатам факторного анализа

\begin{tabular}{|c|c|c|c|}
\hline & \multicolumn{3}{|c|}{ Кластер } \\
\hline & 1 - Прагматики & $\begin{array}{c}2 \text { - Профессионалы- } \\
\text { материалисты }\end{array}$ & 3 - Идеалисты \\
\hline Профессионализм & $-1,25361$ & 0,60416 & 0,14870 \\
\hline Комфорт & 0,09085 & 0,48959 & $-1,24163$ \\
\hline Постматериализм & $-0,29635$ & $-0,04416$ & 0,46663 \\
\hline Число наблюдений & 32 & 60 & 26 \\
\hline
\end{tabular}

направленностью на него) и четко проявленную противонаправленность профессионамизму - в целом это наиболее «умеренный» кластер из трех выделенных нами); 2) «профессионалы-материалисты», или профматы (учитывая их выраженную связь с профессионализмом и комфортом, и почти индифферентное отношение к постматериализму с мегкой противонаправленностью - это самый большой по объему кмастер: примерно половина всей выборки); 3) «идеалисты» (которые четко связаны с постматериализмом и жестко противонаправлены фактору комфорта).

И эти три группы демонстрируют несколько разные стратегии адаптации к карантинной ситуации (см. Табкицу гі).
В частности, наиболее «обреченными» на поиск работы оказываются прагматики и профматы, тогда как идеалисты странным образом являются наиболее успешными в сохранении своего места - даже если с Аистанцированием работы). Больше прагматиков среди тех, кто «в отпуске по собственному желанию» (кстати, действительно вполне прагматическая стратегия в нынешних усмовиях), а профматов - среди тех, кто «в отпуске». Хотя здесь, конечно, низкая наполненность таблицы (проистекающая из небольшого объема выборки) может вносить свои коррективы в наше исследование, однако сама постановка этого вопроса, как нам кажется, стоит внимания.

Таблица 11

Работают во время карантина представители трех кластеров (в процентах и абсолютных показателях)

\begin{tabular}{lccccccccc}
\hline & & Ищут работу & Уволены & В отпуске & $\begin{array}{c}\text { В отпуске по } \\
\text { собственному } \\
\text { желанию }\end{array}$ & $\begin{array}{c}\text { Работают } \\
\text { удаленно }\end{array}$ & $\begin{array}{c}\text { Работают } \\
\text { стационарно }\end{array}$ & Всего \\
\hline Прагматики & $\mathrm{N}$ & 4 & 0 & 0 & 3 & 7 & 18 & 32 \\
\cline { 2 - 10 } & $\%$ & $12,5 \%$ & $0,0 \%$ & $0,0 \%$ & $9,4 \%$ & $21,9 \%$ & $56,3 \%$ & $100,0 \%$ \\
\hline Профматы & $\mathrm{N}$ & 10 & 0 & 3 & 1 & 21 & 24 & 60 \\
\cline { 2 - 10 } & $\%$ & $16,7 \%$ & $0,0 \%$ & $5,0 \%$ & $1,7 \%$ & $35,0 \%$ & $40,0 \%$ & $100,0 \%$ \\
\hline Идеалисты & $\mathrm{N}$ & 1 & 1 & 0 & 0 & 8 & 14 & 26 \\
\cline { 2 - 10 } & $\%$ & $3,8 \%$ & $3,8 \%$ & $0,0 \%$ & $0,0 \%$ & $30,8 \%$ & $53,8 \%$ & $100,0 \%$ \\
\hline Всего & $\mathrm{N}$ & 15 & 1 & 3 & 4 & 36 & 56 & 118 \\
\cline { 2 - 10 } & $\%$ & $12,7 \%$ & $0,8 \%$ & $2,5 \%$ & $3,4 \%$ & $30,5 \%$ & $47,5 \%$ & $100,0 \%$ \\
\hline
\end{tabular}


Именно через такую постановку мы обращаемся к проблемам, связанным с работой на карантине, у преАставителей разцичных кмастеров (см. Таблицу І2), где проблемы с зарплатой Аля удобства анализа мы объединили в оАин признак.

При этом профматы и идеалисты активнее прагматиков говорят о возникновении проблем (особенно с преАложениями неоп ачиваемых отпусков и с зарплатой), тогАа как прагматики оценивают свою карьерную траекторию наиболее оптимистически. Такой парадокс может объясняться не искмючительно объективными проблемами ими их наличием, а субъективными факторами - в частности, способами интерпретации проблем в различных кластерах, выделенных нами. Это же иц юстрируется и тем фактом, что среди тех, у кого проблем с самоощущением не возникцо, прагматиков более трети (34,I\%), тогда как среди тех, у кого проблемы

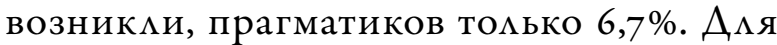
сравнения: идеалистов среди первых только I $8,8 \%$ (при среднем показателе по выборке 22,0\%), среди вторых - 30,0\%. Аоминируют в обеих группах профессионацы-материалисты, однако если среАи тех, Аһя кого проблемы возникАи, их почти Аве трети (63,3\%), то среАи тех, ААя кого они не возникми - меньше поАовины (47,1\%).

Причем о полном отсутствии проблем заявили 53,1\% прагматиков, о том, что они верну-

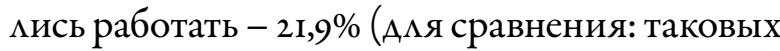
среАи профматов - соответственно, 35,०\% и II,7\%, среди идеалистов - 42,3 \% и 3,8\% [!!!]). Профматы кучше Аругих справляются с Аистанционной работой (таких 20\% при примерно I5,5 +/- о,г\% в Аругих кластерах). Профматы и идеалисты чаще сталкиваются с поисками работы II,6+/-o,1\%), чем прагматики (6,3\%), с временными вариантами работы (соответственно, Іо,о\% и $15,4 \%$ против о\% среди прагматиков) и долговременными поисками работы (соответственно, Іо,о\% и 7,7\% против о\% среди прагматиков).

Конечно, все это влияет, в том числе, на взгляды представителей различных кцастеров на ситуацию на рынке труда и на (допустимые или недопустимые) профессиональные стратегии. В частности, здесь показате ьно восприятие преАставите ями этих кцастеров причин стать трудовыми мигрантами (см. Таблицу 13), которое мы предлагаем проанализировать в средних (где 5,0 - «полностью согласен», І,о - «полностью не согласен»).

Мы обнаруживаем, что именно взгляд профматов явцяется наиболее насыщенным: они

Таблица 12

Проблемы на работе на карантине упредставителей трех кластеров (в процентах и абсолютных показателях)

\begin{tabular}{|c|c|c|c|c|c|c|}
\hline & & Не возникло & $\begin{array}{c}\text { Предложили } \\
\text { уволиться }\end{array}$ & $\begin{array}{c}\text { Предложили } \\
\text { неоплачиваемый } \\
\text { отпуск }\end{array}$ & $\begin{array}{c}\text { Проблемы с } \\
\text { зарплатой }\end{array}$ & Всего \\
\hline \multirow[t]{2}{*}{ Прагматики } & $\mathrm{N}$ & 26 & 0 & 0 & 5 & 32 \\
\hline & $\%$ & $81,3 \%$ & $0,0 \%$ & $0,0 \%$ & $15,6 \%$ & $100,0 \%$ \\
\hline \multirow{2}{*}{$\begin{array}{l}\text { Профессионалы- } \\
\text { материалисты }\end{array}$} & N & 36 & 2 & 4 & 16 & 60 \\
\hline & $\%$ & $60,0 \%$ & $3,3 \%$ & $6,7 \%$ & $26,6 \%$ & $100,0 \%$ \\
\hline \multirow[t]{2}{*}{ Идеалисты } & $\mathrm{N}$ & 16 & 0 & 2 & 7 & 26 \\
\hline & $\%$ & $61,5 \%$ & $0,0 \%$ & $7,7 \%$ & $26,9 \%$ & $100,0 \%$ \\
\hline \multirow[t]{2}{*}{ Всего } & N & 78 & 2 & 6 & 28 & 118 \\
\hline & $\%$ & $66,1 \%$ & $1,7 \%$ & $5,1 \%$ & $23,7 \%$ & $100,0 \%$ \\
\hline
\end{tabular}


Таблица 13

Представители трех кластеров о том, что подталкивает украинцев стать трудовыми мигрантами (в средних и среднеквадратических отклонениях)

\begin{tabular}{|c|c|c|c|c|c|c|}
\hline & \multicolumn{2}{|c|}{ Прагматики } & \multicolumn{2}{|c|}{ Профматы } & \multicolumn{2}{|c|}{ Идеалисты } \\
\hline & Среднее & CKO & Среднее & СКО & Среднее & CKO \\
\hline Более высокая заработная плата & 4,38 & 1,157 & 4,65 & 0,659 & 4,69 & 0,679 \\
\hline Более высокий уровень жизни & 4,13 & 1,157 & 4,57 & 0,745 & 4,35 & 0,689 \\
\hline Лучшие условия труда & 3,37 & 1,362 & 4,15 & 0,954 & 3,27 & 1,313 \\
\hline $\begin{array}{l}\text { Глобальный мир, который предлагает украинцам } \\
\text { возможности в других странах }\end{array}$ & 3,47 & 1,344 & 4,05 & 1,032 & 3,62 & 1,169 \\
\hline Безнадежность по делам на родине & 3,44 & 1,076 & 3,92 & 1,197 & 3,46 & 1,240 \\
\hline Невозможность реализоваться как специалист & 3,25 & 1,320 & 3,92 & 1,013 & 3,42 & 1,137 \\
\hline Отсутствие жизненных перспектив & 3,47 & 1,218 & 3,87 & 1,214 & 3,54 & 1,392 \\
\hline Нестабильная политическая ситуация в Украине & 3,34 & 1,428 & 3,87 & 1,171 & 3,50 & 1,030 \\
\hline Произвол в стране, отсутствие правового государства & 3,19 & 1,281 & 3,82 & 1,066 & 3,19 & 1,327 \\
\hline Лучшая медицина за рубежом & 3,44 & 1,243 & 3,77 & 1,226 & 3,62 & 1,061 \\
\hline Нет ощущения безопасности и защищенности & 3,13 & 1,070 & 3,75 & 0,939 & 3,12 & 1,143 \\
\hline Отсутствие работы в Украине & 3,03 & 1,448 & 3,65 & 1,233 & 3,38 & 1,235 \\
\hline Семейные обстоятельства & 2,88 & 1,157 & 3,55 & 1,048 & 3,38 & 1,023 \\
\hline Случайные обстоятельства & 3,09 & 1,058 & 3,42 & 1,094 & 3,46 & 0,989 \\
\hline $\begin{array}{l}\text { Семейно-брачные отношения, объединение } \\
\text { с близкими }\end{array}$ & 2,94 & 1,076 & 3,25 & 1,202 & 3,15 & 1,047 \\
\hline $\begin{array}{l}\text { Потребность в обновлении жизни, культуре } \\
\text { и знаниях }\end{array}$ & 3,16 & 1,247 & 3,17 & 1,368 & 3,08 & 1,164 \\
\hline Массовые беспорядки & 2,87 & 1,264 & 3,05 & 1,032 & 2,69 & 1,087 \\
\hline Необходимость изменений климатических условий & 2,81 & 1,256 & 2,83 & 1,122 & 2,27 & 1,185 \\
\hline Стихийные бедствия & 2,56 & 1,216 & 2,65 & 1,162 & 2,35 & 1,056 \\
\hline Сумма средних по всем признакам & 61,95 & & 69,91 & & 63,54 & \\
\hline
\end{tabular}

готовы допустить больше разАичных причин ААя того, чтобы стать трудовыми мигрантами (нужно понимать, что этот вопрос работает, в том числе, как проективный вопрос о том, что именно могло бы повииять на самих респондентов в таком выборе). Так, профматы мидируют по подав яющему большинству показатемей (кроме «скучайных обстоятемьств» и «более высокой заработной платы», где все же несколько - но ненамного - выше показатели у идеалистов). Показательно, что при этом прагматики очень реАко выхоАят даже на второе место среди кцастеров, приближаясь к мидерским показателям только в признаке «потребность в обновлении жизни, новой кумьтуре и знаниях» (но этот признак вообще демонстрирует очень плотные показатели Аля всех кластеров) и занимая вторую позицию по таким признакам, как «массовые беспорядки», «кмиматические условия», «стихийные беАствия», «лучшие условия труда», «безнадежность в делах на родине», «беспредел в стране» и «нет ощущения безопасности и защищенности». Как видим, «прагматики» чаще могут допустить или политические причины (беспорядки, 
безнадежность, произвол, опасность), ими естественные причины (кмимат, бедствия), ици только один экономический фактор (Аучшие условия труда). Это тоже является важным штрихом к общему портрету этих кластеров.

\section{Рефлексия и выводы}

Таким образом, харьковская молодежь действительно демонстрирует разАичные стратегии приспособления и аАаптации к новой пандемической ситуации и ее экономическим последствиям (Аокдаунам, карантинам, сокращениям, Аистанционной работе и т.п.). Эти стратегии могут быть исследованы и описаны как чисто Аинейно-прямыми способами измерения (в частности, отталкиваясь от проблем, с которыми встречается молодежь на рынке труда, или от возникающих на нем ограничений), так и исследованием глубинных структур детерминации ценностных, повседневностных, экономических, профессионально-трудовых и т.А. аспектов жизни молодежи. При этом выделенные нами кластеры в целом являются «узнаваемыми», а их небольшое количество (всего три кмастера) может быть объяснено как спецификой исследования, так и тем, что в условиях карантинной специфической ситуации мы встречаемся с редуцированием, упрощением и упцощением многообразия профессиональных и трудовых акторов.

Проведенное нами исследование, безус-

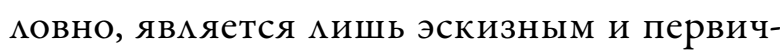
ным, фактически только контурной попыткой очертить кмючевые возможные точки и пределы целой исследовательской области. Его ограничения являются многообразными и различными: начиная с парадигматических (как видно из текста работы, мы не ставили себе целью формулировать важные и универсальные обобщения парадигматического уровня), общетеоретических (мы осуществ я $\Lambda и$ искАючите ьно эмпирический анациз, поэтому наши выводы не являются теоретически экстраполируемыми и вмонтированными в более широкие конструкции и концепты) - и заканчивая методологическими: веАь понятно, что как специфика выборки, так и специфика избранной нами методомогии ограничивает аппмицируемость наших результатов. При этом следует понимать, что имплицитные структуры, которые мы находим как факторным, так и кластерным образом, являются более устойчивыми, чем распределения, тенденции и дифференциации, - и, следовательно, эти структуры с высокой степенью вероятности будут найдены нами и в Аальнейших исследованиях, а само их обнаружение Ааже в таком эскизном исследо-

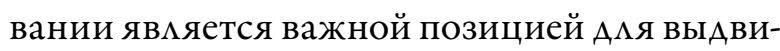
жения Аацьнейших гипотез и индикаторов.

Собственно, именно здесь открываются важные перспективы даАьнейшего исследования данной проблематики. Вычленения кАастеров в трудовых группах, сравнение кмастерной структуры разАичных социоАемографических и экономических групп и к ассов, анализ факторов их трудового поведения и трудовых ценностей - все это Аолжно быть раскрыто в Аальнейших исслеАованиях уже не только как сугубо артефакты на рынке труда, но и как социоинженерный объект, как научные конструкты (то есть как социологические категории, изобретенные ААя описания причин и процессов становмения именно таких кмастеров). Пандемия, которая выступила как хайдеггеровский слом привычного предмета (разоблачив тем самым настоящую структурность и функционацьность этого преАмета), не только ставит переА социологами новые проблемы и вызовы, но и предоставцяет в этом отношении новые возможности. 


\section{Библиография}

Agamben, Dž. (2020). Rekviem po studentam. Režim dostupa: https:// centerforpoliticsanalysis.ru/position/read/id/rekviem-po-studentam [dostup: 9.04.2021].

Burd'e, P. (1993). Sociologiâ politiki: Sbornik statej. Moskva, Socio-Logos.

Burd'e, P. (1996). Universitetskaâ doksa i tvorčestvo: protiv sholastičeskih delenij. V: Socio-Logos'96. Al'manah Rossijsko-francuzskogo centra sociologičeskih issledovanij Instituta sociologii Rossijskoj Akademii nauk (s. 8-31). Moskva: Socio-Logos.

Fukuyama F. (2020). The Pandemic and Political Order. Режим доступа: https://www.foreignaffairs.com/articles/world/2020-06-09/ pandemic-and-political-order [dostup: 9.04.2021].

Hasuev, A.è. (2020). Social'naâ izolâciâ i samoizolâciâ čeloveka: social'nofilosofskij analiz. Èkonomičeskie i gumanitarnye issledovaniâ regionov, № 2, 122-128.

Klâjn, N. (2020). Novyj cifrovoj kurs: vysokotehnologičnaâ utopiâ v èpohu koronavirusa. Režim dostupa: http://rabkor.ru/columns/ analysis/2020/05/25/new-digital-cours_high_tech_dystopia_in_ the_era_of_coronavirus/ [dostup: 9.04.2021].

Martirosân, 0.A. (2020). Molodežnaâ zanâtost' i bezrabotica v usloviâh pandemii COVID-19. Vestnik BIST, 3, 69-74.

Mironova, T.A. (2020) Transformaciâ kommunikativnyh interesov i navykov studentov v period pandemii KOVID-19: social'nye, političeskie i duhovnye aspekty. Vestnik BIST, 2, 36-43.
Novaâ molodežnaâ povestka: Novye formy razvitiâ i podderžki molodeži v period pandemii, vyzvannoj COVID-19. (2020). Režim dostupa: https://files.asi.ru/iblock/82f/82fc99b6a79e07c750345a0372af05ab/ ASI-VSHE-Novaya-molodezhnaya-povestka.pdf [dostup: 9.04.2021]. OECD Policy Responses to Coronavirus. Youth and Covid-19: Response, Recovery and Resilience. (2020). Режим доступа: https://read.oecdilibrary.org/view/?ref=134_134356-ud5k0x3g26\&title=Youth-andCOVID-19-ResponseRecovery-and-Resilience [dostup: 9.04.2021].

Sokurânskaâ, L.G. (2006). Studenčestvo na puti k drugomu obŝestvu: cennostnyj diskurs perehoda. Har'kov: Har'kovskij nacional'nyj universitet imeni V.N. Karazina.

Sokurânskaâ, L.G., Kislova, 0.N. (2003). Cennostnaâ differenciaciâ ukrainskogo studenčestva: klasternyj analiz. V: Metodologiâ, teoriâ ta praktika sociologičnogo analizu sučasnogo suspil'stva. Zbirniknaukovih

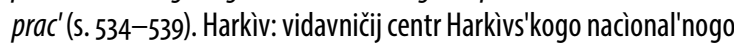
universitetu.

Turkulec, S.E., Turkulec, A.V., Listopadova, E.V., Sokol'skaâ, M.V. (2020). Social'naâ stigmatizaciâ v period pandemii. Sociodinamika, $9(2), 11-25$. Volkov, V.V., Harhordin, O.V. (2008). Teoriâ praktik. Sankt-Peterburg: EU SPB.

Volkov, Û.G., Kurbatov, V.I. (2020). Global'naâ sociologiâ pandemii: otečestvennye i zarubežnye scenarii i trendy poslekoronavirusnogo mira. Gumanitarij Ûga Rossii. t. 9, № 2, 17-32.

Zaharkina, N.V., Alëhina, T.A., Mosina, E.I. (2020). Trudoustrojstvo molodyh specialistov: реалии, problemy i perspektivy. Vestnik OrelGIÈT, 2, $156-162$.

Zizek, S. (2020). Pan(dem)ic!! COVID-19 shakes the world. New York: OR Books. 